\title{
Mediação de leitura através dos Instagrans literários
}

\author{
Reading mediation through bookstagrans
}

\author{
Anamaria Barreto Nascimento \\ Bacharel em Biblioteconomia e Documentação \\ Universidade Federal de Sergipe \\ anabarrt@gmail.com
Martha Suzana Cabral Nunes
Doutora em Ciência da Informação
Universidade Federal de Sergipe
marthasuzana@hotmail.com

\begin{abstract}
Resumo
Nas mídias sociais, as pessoas buscam encontrar quem compartilha dos mesmos interesses. Hoje em dia, com os avanços das Tecnologias da Informação e Comunicação, é possível encontrar na web variadas mídias sociais voltadas para os leitores. Os Instagrans literários são perfis criados na plataforma do Instagram com o intuito de divulgar livros, aproximar pessoas com gostos de leitura similares e criar uma comunidade literária. Dessa forma, o objetivo geral dessa pesquisa foi verificar a contribuição dos perfis literários no Instagram como mediadores de leitura. Entre os objetivos específicos estão: caracterizar as formas de mediação de leitura e de atuação do bibliotecário como mediador de leitura; compreender o uso das mídias sociais no incentivo à leitura; contextualizar o espaço do bookstagram e analisar esses perfis e suas interações com seus seguidores. Quanto à metodologia, essa é uma pesquisa descritiva com abordagem de natureza qualitativa e quantitativa. Como instrumento para coleta de dados foram aplicados questionários eletrônicos com o objetivo de analisar a interação dos perfis literários com seus seguidores, além das percepções pessoais desses moderadores em relação à forma como eles medeiam a leitura. Conclui-se que os Instagrans literários contribuem ativamente na mediação da leitura digital através das ferramentas utilizadas para a criação de conteúdo e que os leitores atuam como os próprios mediadores da leitura.
\end{abstract}

\section{Palavras-chave}

Instagram literário. Mediação da leitura. Mídias sociais. Bookstagram.

\begin{abstract}
On social media, people seek to connect with others who share their same interests. Today, with the advancements of Information and Communication Technologies, it is possible to find various social media platforms for readers. Literary Instagrams, or bookstagrams, are profiles created on the Instagram platform with the purpose of sharing books, connecting people with similar literary tastes, and to create a community of readers. As such, the general objective of this research was to analyze the contribution of literary profiles on Instagram as reading mediators. Among the specific objectives are to characterize the forms of reading mediation and the role of the librarian as reading mediator; to understand the use of social media to encourage reading; to contextualize the bookstagram space and analyze these profiles and their interactions with their followers. As for the methodology, this is a descriptive research with a qualitative and quantitative approach. As a tool for data collection, electronic questionaries were applied in order to analyze the interaction of literary profiles with their followers, in addition to their personal perceptions of these moderators in relation to how they mediate
\end{abstract}


reading. In conclusion, bookstagrams actively contribute to the mediation of reading through the tools used for the creation of content, and readers acting as their own mediators.

\section{Keywords}

Bookstagram. Reading mediation. Social media. Literary Instagram.

\section{INTRODUÇÃO}

$\mathrm{O}$ ato de ler evoluiu ao longo da história da humanidade. Antes a leitura era praticada apenas por um grupo limitado de pessoas, com o passar do tempo se tornou mais democratizada e é também uma forma de lazer para muitos. Os avanços das Tecnologias de Informação e Comunicação (TIC) não trouxeram apenas a facilidade em se trocar informações e interações de forma instantânea, como também possibilitaram o surgimento de novas práticas de leitura. Tablets, smartphones e e-readers, ou leitores digitais, dispositivos próprios para a leitura, são exemplos de como ler se tornou mais prático.

Contudo, apesar desses avanços, a pesquisa Retratos da Leitura no Brasil, realizada pelo Instituto Pró-Livro no ano de 2016, revelou que foram lidos naquele ano em média 4,96 livros por brasileiro, sendo 2,43 livros inteiros e 2,53 apenas fragmentos. A mesma pesquisa apontou que $43 \%$ dos entrevistados afirmaram gostar um pouco de ler e $30 \%$ que gostam muito, enquanto $23 \%$ declararam não gostar de ler livros. Entre os motivos da falta de frequência de leitura, 43\% das pessoas afirmaram não terem tempo (FAILLA, 2016).

Por outro lado, existem pessoas que não só mantêm o hábito de ler, como se utilizam das TIC para que a leitura seja compartilhada e disseminada por meio das mídias sociais como blogs, Facebook, Twitter, Tumblr e Instagram, onde as pessoas criam perfis e páginas com o propósito de falar sobre livros.

Foi com essa proposta que surgiu o Instagram literário, ou bookstagram, termo original da língua inglesa, que compreende perfis criados na plataforma do Instagram com o intuito de divulgar livros, mediar a leitura, aproximar pessoas com gostos de leitura similares e, assim, criar uma comunidade literária. Nesses perfis, através de resenhas, indicações, maratonas e desafios literários, entre outros tipos de conteúdo, é possível conhecer novos autores, aproximar-se de outros leitores e até formar novos leitores.

Sendo assim, entende-se que os criadores de conteúdo dos Instagrans literários surgem como mediadores de leitura, com o desafio de estimular e levar os livros aos seus seguidores. Esses perfis têm como proposta incentivar a leitura em um ambiente favorável, que são as mídias sociais. Mas, de que forma é feita a mediação de leitura através dos Instagrans literários?

Nesse mesmo cenário, os bibliotecários, como mediadores de leitura, podem e devem se apropriar das novas mídias para estimular a leitura e, consequentemente, formar novos leitores. É um caminho que se abre na prática do profissional, que pode usufruir das variadas redes disponíveis e executar o seu papel como mediador da leitura.

Diante desse contexto e do questionamento posto, essa pesquisa teve como objetivo geral verificar a contribuição dos perfis literários no Instagram como mediadores de leitura. Entre os objetivos específicos estão: caracterizar as formas de mediação de leitura e de atuação do bibliotecário como mediador de leitura; compreender o uso das mídias sociais no incentivo à leitura; contextualizar o espaço do bookstagram e analisar esses perfis e suas interações com seus seguidores.

A leitura tem um papel de extrema importância no desenvolvimento cognitivo do ser humano, que molda seu senso crítico e o transforma em um indivíduo mais consciente 
de si e do mundo que o cerca. Além disso, o ato de ler desenvolve a imaginação, a criatividade, aumenta o vocabulário, aperfeiçoa a escrita e expande a percepção da diversidade cultural em que se vive.

Ao se apropriar desse contexto e utilizarem uma linguagem coloquial e objetiva, fotos e conteúdos criativos, os Instagrans literários podem incentivar cada vez mais novos leitores, visto que o Instagram é uma das redes sociais que mais crescem e que tem um grande poder de influência entre seus seguidores. Câmara (2019) destaca que o Instagram possui mais de 1 bilhão de usuários em todo mundo, com o Brasil sendo o segundo país com maior número de consumidores, ficando atrás dos Estados Unidos.

Essa pesquisa aborda um tema atual, que vem sendo cada vez mais pesquisado e discutido, e se justifica por discutir, assim com encontrado em Santos Neto (2020) e Correa (2015), a importância da leitura e de que forma ela pode ser incentivada e mediada através da mídia social Instagram, que tem um amplo alcance entre seus usuários.

\section{LEITURA}

A definição mais moderna para leitura, relata Fischer (2006), a compreende como a capacidade de retirar sentido de textos escritos, impressos ou digitais. Inicialmente, a leitura era compreendida como mera possibilidade da obtenção de informação, tendo como base um sistema codificado e o entendimento de seu significado (FISCHER, 2006).

Ao enxergar a leitura em um sentido mais amplo, fora da escola e para além do texto escrito, é possível entender que ela "permite a descoberta de características comuns e diferenças entre indivíduos, grupos sociais, as várias culturas; proporcionando elementos para uma postura crítica [...]" (MARTINS, 2007, p. 29).

Sob essa perspectiva, para se obter êxito na prática da leitura é necessário que o indivíduo compreenda o que é lido, interprete e contextualize suas percepções com seu convívio social. Ao entrar em contato com o texto, o leitor precisa estar posicionado como um elemento ativo à procura dos sentidos que, muitas das vezes, encontram-se implícitos no texto. Para isso, é necessário que durante a leitura haja um diálogo entre texto e leitor na busca de apreensão de sentidos.

Dessa forma, Koch e Elias (2010, p. 11) concordam que:

\footnotetext{
o sentido de um texto é construído na interação texto-sujeitos e não algo que preexista a essa interação. A leitura é, pois, uma atividade interativa altamente complexa de produção de sentidos, que se realiza evidentemente com base nos elementos linguísticos presentes na superfície textual e na sua forma de organização, mas requer a mobilização de um vasto conjunto de saberes no interior do evento comunicativo.
}

Nesse contexto, a leitura pode ser caracterizada como um processo produtor de sentidos que, além de contar com os conhecimentos prévios do leitor, exige que o mesmo se posicione ativamente diante do texto. O leitor passa a ser, então, um construtor de sentidos diante do texto, de forma que faz uso de seu conhecimento de mundo, de suas habilidades e suas experiências e até mesmo de suas emoções para formação do entendimento que será atribuído ao texto.

A leitura está diretamente ligada à democracia, à liberdade do indivíduo em entender de onde ele veio, aprender mais sobre si e seus semelhantes, seus direitos e deveres como cidadão crítico e consciente. 
A 4a edição da pesquisa "Retratos da Leitura no Brasil" foi realizada em 2016 pelo Instituto Pró-Livro, o qual tem como objetivo promover a leitura e o acesso aos livros. O foco principal dessa edição da pesquisa foi conhecer o comportamento do leitor brasileiro através de parâmetros como forma, limitações, intensidade e motivações de leitura, além das condições e do acesso aos livros, tanto impressos como digitais.

Os perfis de amostra da pesquisa foram divididos entre gênero, idade, região e nível de escolaridade. A pesquisa considerou leitor o indivíduo que tinha lido pelo menos um livro nos três meses antecedentes à pesquisa, sendo livros inteiros ou em partes.

Entre as considerações feitas pela pesquisa, $25 \%$ dos entrevistados responderam que a principal motivação para ler era por gostar, $19 \%$ por atualização cultural ou conhecimento e $15 \%$ por distração; $77 \%$ dos leitores gostariam de ter lido mais, e o maior motivo para não ler foi a falta de tempo (43\%). Entre os não leitores, a falta de tempo também foi o maior motivo de não terem lido mais (32\%). No grupo de não leitores, $28 \%$ afirmaram não gostar de ler, $13 \%$ disseram que não têm paciência e $10 \%$ que preferem outras atividades (FAILLA, 2016).

Destaca-se que os livros religiosos são os livros mais lidos entre os brasileiros. Todavia, por conta dos avanços tecnológicos, as leituras de gêneros variados em locais públicos, como nos meios de transporte, vêm aumentando consideravelmente ao mesmo tempo em que, comparado às edições anteriores, grande parte da população passou a ler mais por causa do celular e/ou tablet (FAILLA, 2016).

A presente pesquisa teve como foco explorar a mediação da leitura literária, considerando literatura clássica e best-sellers, sem distinção de gênero, seja romances, contos, fantasias, ficção científica, autoajuda etc.

Rocha (2017) trata a leitura literária como uma forma de conhecer diferentes universos, entrar no mundo do outro e viver diferentes realidades, assim, desenvolvendo sensibilidade e empatia pelo próximo. Além disso, permite conhecer diferentes contexto históricos e culturais, estimulando um aprendizado contínuo.

\section{MEDIAÇÃO}

O termo mediação vem do latim mediatio, mediationis, que quer dizer "intervenção com que se busca produzir um acordo". Utilizada principalmente na Ciência da Informação, mas também apropriada na área de Direito, na qual é entendida como intervenção (NUNES, 2015, p. 88).

É por meio da mediação que o indivíduo aprende e adquire conhecimentos, e então torna-se independente para interagir conscientemente em sociedade. A mediação tem evoluído como conceito na Ciência da Informação e possui diferentes extensões, como a mediação da informação, a mediação cultural e a mediação de leitura.

Para Nunes (2015), a informação é apropriada a partir da mediação, a qual permite a comunicação entre indivíduos, um processo no qual ocorre trocas de experiências e encontro de subjetividades. A autora também destaca a formação como elemento importante para desenvolver a competência mediadora nos bibliotecários, a fim de que se reconheçam como mediadores em quaisquer atividades que desenvolvam nas bibliotecas, e que também possam otimizar as atividades de mediação visando a apropriação da informação.

Mediar é o ato de interferir na apreensão e na apropriação de sentidos dos indivíduos, e é através da mediação da leitura que se forma leitores, os tornando independentes e aptos a lerem e entenderem o mundo. 
Mediar a leitura é ter a responsabilidade de "intervir nas escolhas de leitura de um determinado grupo" (ALMEIDA JÚNIOR; BORTOLIN, 2007, p. 8). Nesse sentido, a mediação da leitura acontece quando se apresentam os livros ao indivíduo, formando-o como leitor, expondo as infinitas possibilidades de leituras existentes.

A mediação da leitura deve contemplar os mais variados coletivos, pois não se restringe a um só público e não ocorre em um só local, como evidencia Santos (2018). Ressalta-se que a mediação da leitura não acontece apenas nas escolas, bibliotecas e unidades de informação; é uma prática que pode estar presente nos mais variados espaços, inclusive no ambiente digital.

Bortolin (2013, p. 425) entende que a mediação da leitura literária é a "interferência casual ou planejada visando a levar o leitor a ler literatura em diferentes suportes e linguagens". Em sua concepção, todos medeiam a leitura de alguma forma, conscientemente ou

não.

O mediador tem como meta incentivar a leitura nos mais variados espaços, independente da faixa etária do leitor e do tipo de leitura. É preciso quebrar tabus e estimular uma leitura diversificada, independente do texto, seja ele "simples, complexo, permitido, proibido, sensual, erótico, informativo, científico, acadêmico, crítico, político, filosófico, ingênuo, religioso, sério, engraçado, de devaneio de lazer, popular, erudito, escrito, falado, imagético, fílmico, cênico etc." (ALMEIDA JÚNIOR; BORTOLIN, 2007, p. 3).

\subsection{O bibliotecário como mediador de leitura}

As práticas de leituras e mediação vêm acompanhando as mudanças tecnológicas da sociedade, e com isso surgem novas formas de ler e de se apropriar das ferramentas disponíveis. Para o bibliotecário, como profissional da informação, esse campo se abre como um espaço repleto de oportunidades para otimizar a mediação da leitura.

O profissional da informação, na visão de Almeida Júnior e Bortolin (2007, p. 8), participa "efetivamente da construção do destino da humanidade". Na mediação, esse profissional colabora de fato na formação de um leitor. O bibliotecário deve ser "cúmplice efetivo e afetivo do leitor", isto é, deve estar aberto a debater ideias sobre as leituras, compartilhar suas experiências pessoais, e não apenas fazer circular os textos.

Diversas são as formas de incentivar a leitura nas redes atualmente. A mediação da leitura tornou-se uma prática dinâmica e interativa e os leitores têm à disposição diferentes plataformas que os estimulam e despertam o gosto pela leitura, bastando escolher a que melhor se encaixa com seu perfil. Quanto ao mediador de leitura, este precisa adequar-se às novas práticas de leitura e usar estratégias para atrair o leitor.

\section{MÍDIAS SOCIAIS}

A partir dos anos 1990 foram surgindo as comunidades virtuais mediadas originalmente pelo computador. Uma comunidade virtual é, segundo Castells (2012, p. 443), "uma rede eletrônica autodefinida de comunicações interativas e organizadas ao redor de interesses em comum, embora às vezes a comunicação se torne a própria meta", ou seja, um grupo de pessoas na internet que se encontram e se comunicam por terem gostos e interesses parecidos. 
Para Lévy (2011, p. 131), as comunidades virtuais "exploram novas formas de opinião pública". Essas comunidades oferecem um espaço para discussões coletivas, no qual é possível se ter debates abertos e participativos. Antes do advento do ciberespaço, grupos de pessoas com interesses em comum, espalhadas ao redor do mundo, não tinham a oportunidade de interagirem entre si. Através das comunidades virtuais, segundo o autor, é possível que essas pessoas tenham um ambiente particular de encontro.

Com os avanços das TIC, as mídias sociais permitem novas formas de produção de conteúdo e leituras. Diniz (2016) afirma que o leitor deixou de ser apenas o receptor da informação; ele também a produz e, através da internet, está sempre em contato com outros leitores que, por sua vez, também estão produzindo conteúdo.

Os leitores, atualmente, buscam velocidade na leitura e é isso o que as mídias sociais permitem. O nível de sociabilidade oferecido pelas mídias é grande e vem trazendo consequências culturais para a sociedade atual. $\mathrm{O}$ ato de ler mudou, tornou-se uma prática interativa e com isso novas práticas de leitura surgem. Nesse contexto, os leitores se apropriam dos variados espaços das mídias sociais para incentivar a leitura e, por consequência, mediá-la. Algumas dessas redes sociais são: blogs, Youtube, Skoob, Goodreads, Wattpad, Livra livro, Cabeceira.

Independentemente da plataforma e do perfil do usuário, nas mídias sociais é possível encontrar perfis das mais variadas temáticas, que criam comunidades e grupos nos quais é possível conhecer e relacionar-se com pessoas de preferências afins. O objeto da presente pesquisa é o Instagram.

O Instagram é uma mídia social de captura e compartilhamento de fotos e vídeos, criada em 2010. É possível seguir outros usuários, ser seguido e curtir, comentar e compartiIhar as publicações. Trata-se de uma mídia social emergente, "pois se constrói através da interação entres usuários, em comentários e discussões que se criam em torno das imagens" (PIRES, 2012, p. 29).

Um perfil ou página no Instagram pode ter sua reputação medida através de fatores como número de seguidores, curtidas e comentários; o conteúdo dos comentários também influencia, pois pode exprimir opiniões positivas ou negativas.

As marcas vêm usando o Instagram como ferramenta de divulgação, visto que as postagens circulam "de modo ainda mais instantâneo as novidades porque já entenderam que é uma ferramenta exitosa para se aproximar dos consumidores por lidar com imagens, as quais operam com o imaginário e o desejo das pessoas" (HINERASKY, 2014, p. 7).

Pelo Instagram é possível encontrar páginas destinadas aos mais variados temas, como moda, esporte, filmes, séries de TV e livros. Os perfis dedicados aos livros são os Instagrans literários, ou bookstagram, termo original da língua inglesa, que é a união dos termos books (livros) e Instagram.

Para Morais (2018, p. 18), o Instagram literário é uma forma de disseminar "conteúdos que são relevantes para determinado grupo de pessoas, construídos diante das particularidades e singularidades que o bookstagrammer possui através de suas experiências com a leitura". Um dos principais objetivos do Instagram literário é divulgar os livros quando estes são lidos e os leitores se conectam à história.

Bookstagrammer é o termo da língua inglesa que designa o moderador do Instagram literário, o criador de conteúdo. Para Bittencourt (2017, p. 23) os bookstagrammers são os "donos de contas no aplicativo exclusivamente dedicadas a falar sobre livros e objetos literários [...]". 
Silva (2016) descreve métodos de postagens comumente utilizados pelos blogs literários, que são recursos também apropriados pelos Instagrans literários para interagirem com seus seguidores:

- Desafios literários: metas que os leitores devem seguir e cumprir em um prazo estabelecido. As tags literárias, por exemplo, consistem em responder perguntas nas quais as respostas devem ser relacionadas aos livros e, ao final, desafia-se outras pessoas a fazerem o mesmo;

- Maratonas literárias: prática de ler um livro ao mesmo tempo durante um prazo estipulado. Geralmente, no bookstagram, as maratonas literárias são mais frequentes durante feriados prolongados ou período de férias. Uma prática muito comum também é a leitura conjunta, que determina um número de páginas ou capítulos, e no final de cada meta cumprida os leitores debatem suas impressões em relação à leitura;

- Projeto de leitura: se assemelha às maratonas literárias, mas alguns projetos podem

levar mais tempo para serem concluídos. Consiste em ler todas as obras de um autor ou séries e livros de um mesmo gênero;

- Sorteios: habitualmente feitos em parcerias com outros perfis, editoras ou autores, é uma forma de atrair mais leitores a visitar e interagir com o perfil. Livros são os prêmios da maioria dos sorteios, mas outros itens relacionados ao universo literário também são sorteados, como capas para livros, ecobags, xícaras, marcadores de páginas etc. As regras são definidas por cada perfil.

Uma das principais ferramentas são as resenhas literárias. Segundo Morais (2018), a resenha do Instagram literário deve consistir em um breve resumo do livro e na opinião pessoal do bookstagrammer.

Outro elemento comum são as parcerias com autores e editoras. De acordo com Morais (2018), as editoras enviam o livro para o bookstagrammer ler e resenhar, com o intuito de atrair novos leitores para adquirirem a obra.

Os bookstagrans são um espaço dinâmico, um canal de entretenimento que acaba desempenhando um papel importante no incentivo à leitura. Independentemente do que a crítica fala de determinada obra ou autor, o Instagram literário existe com o intuito de expressar opiniões pessoais sobre livros que aguçam a curiosidade e que sejam estimulantes. Cada um tem seu critério de avaliação de um livro e o espaço permite que as pessoas interajam e concordem ou não com o que foi postado.

Morais (2018, p. 26) enfatiza que "os bookstagrammers leem apenas pelo simples fato de gostar, consequentemente compartilhando esta experiência com seus seguidores". Nesse contexto, para Bittencourt (2017), os Instagrans literários contribuem com a democratização da leitura, acabando com a concepção de que só os leitores de clássicos e obras canônicas são críticos da literatura.

Esses perfis desenvolvem um papel importante, incentivando a leitura fundamentada no amor pelos livros e não em títulos e prêmios, destacando que o Instagram abre espaço para leitores e críticos comuns.

\section{PROCEDIMENTOS METODOLÓGICOS}

Para a execução desta pesquisa, foi produzido um estudo descritivo, o qual "descreve ou retrata um fenômeno ou objeto de investigação mediante um estudo realizado em de- 
terminado contexto espacial e temporal" (DUARTE; FURTADO, 2014, p. 26). Em relação à abordagem, a presente pesquisa é de natureza qualitativa e quantitativa. Qualitativa porque tem caráter subjetivo e foca na análise de conteúdo; quantitativa pois se utiliza de análises estatísticas nas interpretações dos dados, de acordo com Gil (2010).

A amostra foi definida através do critério de acessibilidade ou conveniência que, de acordo com Gil (2010), se dá quando o pesquisador escolhe os elementos que têm alcance, admitindo que podem representar o universo. Seguindo essa premissa, a população e a amostra da pesquisa compreenderam os bookstagrammers, ou seja, os moderadores dos Instagrans literários, pois tem a intenção de entender de que forma ocorre a mediação de leitura através desses perfis. Desta forma, a interação dos perfis com seus usuários foi analisada, além das percepções pessoais desses moderadores em relação à forma como eles incentivam a leitura através da mídia social Instagram.

Alguns dos critérios para as escolhas dos perfis foram o número de seguidores - a partir de 10 mil, a frequência de postagens e interações através dos stories, que geram mais alcance e interações. Os questionários foram elaborados na plataforma GoogleForms e o envio para os administradores dos perfis foi feito através de mensagem direta (direct) no Instagram e/ou e-mail. De 30 perfis literários obteve-se no total 53,33\% de retorno.

Os perfis dos Instagrans literários que participaram da pesquisa foram: Curta Leitu$\mathrm{ra}^{1}$, De Livro não me Livro ${ }^{2}$, Entre Páginas e Café ${ }^{3}$, Leitura como Hobby ${ }^{4}$, Livros Terapia ${ }^{5}$, Meu Cantinho Literário ${ }^{6}$, Minha Secreta Poesia ${ }^{7}$, Namanita $^{8}$, Os Livros da Dani ${ }^{9}$, Páginas da Fran ${ }^{10}$, Peculiares Livros ${ }^{11}$, Profundez ${ }^{12}$, Rany Books ${ }^{13}$, Sobre Ler ${ }^{14}$, Sobre um Livro ${ }^{15}$, Stefânia Cedro ${ }^{16}$. Todos foram informados sobre os objetivos da pesquisa e concordaram em participar voluntariamente.

\section{RESULTADOS E DISCUSSÃO}

O perfil do Instagram é como se fosse o "cartão postal" para os visitantes, por isso os bookstagrammers atualizam as suas biografias com informações que julgam relevantes, se apresentando ao informar nome, idade e cidade de residência, e informando o que a pessoa irá encontrar no perfil, como o conteúdo literário (resenhas, dicas), além de outros tipos de assunto que podem ser relacionados ou não à literatura (filmes, séries).

As hashtags utilizadas pelos perfis também são uma ferramenta comumente utilizada nas biografias, de maneira que fique mais fácil de encontrar resenhas ou outro tipo de con-

\footnotetext{
${ }^{1}$ https://www.instagram.com/curtaleitura/

${ }^{2}$ https://www.instagram.com/delivronaomelivro/

${ }^{3}$ https://www.instagram.com/entrepaginasecafe/

${ }^{4}$ https://www.instagram.com/leituracomohobby/

${ }^{5}$ https://www.instagram.com/livros_terapia/

${ }^{6}$ https://www.instagram.com/meucantinho_literario/

${ }^{7}$ https://www.instagram.com/minhasecretapoesia/

${ }^{8}$ https://www.instagram.com/namanita/

${ }^{9}$ https://www.instagram.com/oslivrosdadani/

${ }^{10}$ https://www.instagram.com/paginasdafran/

${ }^{11}$ https://www.instagram.com/peculiareslivros/

12 https://www.instagram.com/profundez/

${ }^{13}$ https://www.instagram.com/ranybooks/

${ }^{14}$ https://www.instagram.com/sobre.ler/

${ }^{15}$ https://www.instagram.com/sobreumlivro/

${ }^{16}$ https://www.instagram.com/stefaniacedro_/
} 
teúdo, visto que a ferramenta é uma forma de categorizar os posts. Cada perfil cria sua própria hashtag para diferentes conteúdos como as resenhas, indicações etc.

Como forma de analisar a motivação, foi questionado o porquê de os respondentes terem criado um perfil no Instagram. A grande maioria respondeu que o maior estímulo foi pessoal, com o objetivo de compartilhar suas leituras. Alguns não tinham com quem conversar sobre livros dentro do seu círculo de amigos e familiares, outros porque sempre gostaram de postar momentos da vida pessoal nas redes sociais e foi natural compartilhar as leituras até o perfil se tornar exclusivamente literário.

Silva (2016), em estudo realizado com blogs literários, identificou que as motivações dos blogueiros se assemelham às mesmas que as dos Instagrans literários. Expor e compartiIhar suas experiências literárias, atualizar-se sobre as notícias do mercado editorial e poder se relacionar com outros leitores pelo fato de não haver pessoas próximas com quem conversar sobre o universo literário estão entre as motivações elencadas.

Constatou-se que a maioria dos Instagrans literários tem entre 1 e 5 anos de existência. Dessa forma, identificou-se que a prática de se utilizar do Instagram para falar sobre livros e literatura é recente, e está em constante crescimento.

Bittencourt (2017) afirma que foi entre 2014 e 2015 que o Instagram passou a ser uma das primeiras fontes de busca para leitores que pesquisavam mais sobre livros. $\mathrm{O}$ fato de o Instagram ser uma mídia social intuitiva e dinâmica contribui para essa expansão e é perceptível que muitos blogs literários se utilizam hoje do bookstagram para divulgar seus blogs e posts, prática potencializada pela pandemia do novo Coronavírus.

Foi questionado se os bookstagrammers possuíam uma equipe de profissionais para trabalhar no seu perfil, seja designers, revisores de português ou bibliotecários, e todos responderam que não. Conclui-se, então, que cada um mantém o seu perfil de forma autônoma, desde a produção de conteúdo até o gerenciamento do perfil, como interação com seguidores etc.

Outro fator explorado no questionário foi se os moderadores do Instagram literário já fizeram algum curso ou treinamento para atuar no bookstagram ou desenvolvendo a leitura. Todos os respondentes apontaram que não. A maioria afirmou ter aprendido a utilizar as ferramentas disponíveis com o tempo ou perguntando a amigos e conhecidos, e um dos respondentes afirmou que sua formação em Jornalismo pôde contribuir nas práticas do Instagram.

Bittencourt (2017, p. 62) analisa que as práticas do Instagram literário podem despertar identificação com atividades que a pessoa antes não praticava, "atividades que antes eram hobby - fotografia, leitura, habilidade em escrever resenhas - se tornam um portfólio que abre caminho para trabalhos". Ou seja, através do bookstagram pode ser que a pessoa descubra um talento que antes não era explorado.

Através da análise dos perfis, foi possível observar que a formação de cada bookstagrammer reflete nos seus posts. Uma estudante de psicologia aborda no seu perfil livros da área ou indica leituras sobre essa temática. Uma professora de inglês pode trazer em seu perfil livros da língua inglesa, dá dicas de como melhorar a leitura no idioma etc. Uma mãe fala sobre sua rotina com os filhos e como é sua relação com a literatura e a rotina atarefada. Cada perfil contém a personalidade da pessoa que está criando o conteúdo.

Para caracterizar os conteúdos de cada Instagram literário, os bookstagrammers foram questionados sobre a frequência de atividades no perfil e sobre as ferramentas e os recursos mais utilizados. 
Foi possível constatar que a maioria é bastante ativa no seu perfil, sendo que $50 \%$ atualiza o perfil de 3 a 4 vezes por semana e 12,5\% diariamente. A parcela que atualiza o Instagram literário de 1 a 2 vezes por semana corresponde a 12,5\%, o que ainda representa uma frequência constante. Dos perfis, $25 \%$ não têm padrão de atualização, ou seja, não segue um cronograma e atualiza o seu perfil de acordo com seus próprios parâmetros.

Os perfis que estão sempre atualizando suas contas, seja diariamente ou 3 a 4 vezes por semana, mantêm, em sua maioria, um cronograma pré-definido de posts, com a ideia de não se tornar repetitivo e diversificar os conteúdos.

Silva (2016) afirma que quanto mais atualizado é o perfil literário mais interação se recebe, fidelizando os leitores a frequentarem a página, pois sabem que está sempre produzindo conteúdo. Perfis que não postam regularmente acabam por perder interação e, consequentemente, seguidores.

Todos os perfis trabalham com resenhas, o que indica que essa é a ferramenta mais comum utilizada no Instagram literário. Sorteios $(87,5 \%)$ e Tags literárias (81,3\%) são outras das ferramentas mais utilizadas, seguidas de Projetos de leitura (68,8\%), como por exemplo leitura conjunta, Maratonas literárias $(50 \%)$ e Desafios literários $(43,8)$. Essas ferramentas (com exceção dos sorteios) indicam atividades mais interativas, nas quais os mesmos livros ou autores são lidos juntamente com outros perfis, interagindo sobre a experiência de leitura que cada leitor tem.

Enquanto as resenhas são o resumo de uma obra e as percepções pessoais do leitor, os Projetos de leitura, Maratonas e Desafios literários permitem uma interação mais pessoal e dinâmica, pois criam uma rede de leitores que interagem entre si, cada um com espaço para falar sua opinião e vivência.

Já os sorteios têm o intuito trazer mais visibilidade para os perfis; as pessoas participam do sorteio e, consequentemente, interagem mais com os Instagrans literários, divulgam o sorteio em seus perfis e convidam seus seguidores a participar. Para Silva (2016), os sorteios são uma forma de atrair novos leitores ao perfil literário.

Quando questionados se consideram o Instagram uma mídia propícia para o incentivo à leitura, todos respondentes afirmaram que sim. A maioria enxerga o Instagram como uma mídia favorável para propagandas de modo geral, o que também inclui os livros.

Através dos posts no feed e nos stories, por exemplo, os perfis do Instagram literário alcançam não só o público leitor, mas pessoas que nunca leram e que acabam sendo influenciadas pelo que veem. A percepção de alguns dos bookstagrammers é também a de que o Instagram incentiva a leitura porque é uma mídia social de fácil acesso e intuitiva, que permite uma comunicação direta entre seus usuários.

Em relação aos perfis se considerarem mediadores de leitura ou não, a maioria $(68,8 \%)$ acredita que sim, enquanto $18,8 \%$ não tem essa percepção. Ressalta-se que um conceito de mediação e mediador de leitura foi incluído na descrição do questionário eletrônico.

Percebe-se que a mediação da leitura pode ocorrer de forma ocasional, sem planejamento, então entende-se como mediação de leitura o simples fato de despertar o interesse e a curiosidade de uma pessoa em relação a um livro, mesmo que a experiência de leitura do perfil tenha sido negativa. Nessa perspectiva, para Bortolin (2013, p. 425), o mediador de leitura influencia planejada ou casualmente o leitor "a ler literatura em diferentes suportes e linguagens".

Entre os argumentos para considerar-se mediador, os respondentes relatam que percebem, através do retorno de seus seguidores, que já os influenciaram a lerem determinados livros e autores, e que despertam o interesse de leitura através de seus perfis. 
Por isso, é possível afirmar que os leitores, ao se apropriarem do Instagram para falar sobre livros, assumem o papel de mediadores da leitura. Incentivar as pessoas a lerem determinada obra ou autor, sortear um livro e enviar de presente para as pessoas, estimular o

hábito de leitura contínua através de ferramentas como maratonas, desafios e leituras conjuntas, são ações que aproximam os seguidores cada vez mais dos livros e é dessa forma que a mediação da leitura acontece digitalmente.

Quando questionados sobre parcerias com editoras ou autores, constatou-se que a maioria dos perfis possuía parcerias com editoras e três mencionaram parcerias com autores; apenas um Instagram literário não possuía nenhum tipo de parceria.

As parcerias com editoras e autores compreendem uma troca de indicações. 0 Instagram literário recebe os livros, seja a versão física ou digital, para que faça a leitura e resenha, e a editora ou o autor geralmente divulgam os posts do parceiro em seu perfil oficial.

Contudo, Silva (2016) afirma que, quando a resenha é negativa, fica a critério da editora/autor divulgar o post em seus perfis. Ou seja, o perfil literário tem liberdade de dar sua

opinião sincera sobre a obra caso não tenha gostado, mas não é garantido que seu post seja publicado pela parceria, seja a editora ou autor.

Em relação às opiniões sobre parcerias com editoras, são diversos pontos de vista. Muitos concordam que é uma ótima forma de divulgar o trabalho da editora e também do perfil. Através das parcerias, as editoras visam que os Instagrans literários influenciem seus seguidores a adquirirem seus livros. Por isso, alguns perfis relatam que acreditam que muitas

editoras escolhem seus parceiros baseados nos números de seguidores, o que às vezes não significa influência, visto que alguns perfis não se preocupam com gramática ou não têm compromisso com o perfil.

A questão da pressão para ler também foi abordada. Alguns respondentes afirmaram já terem se sentidos pressionados a lerem os livros dentro do prazo imposto pela editora, o que não condiz com o ambiente do Instagram literário, que para muitos é um ambiente de descontração.

Bittencourt (2017, p. 18) ressalta que "a opinião desses influenciadores literários faz com que a audiência sinta segurança para adquirir aquele título, ainda mais por saber que após o término da leitura já tem alguém com quem debater a respeito". Ou seja, é uma influência positiva tanto para as editoras como para os leitores.

As parcerias, para Morais (2018), correspondem ao reconhecimento por parte do mercado editorial de que o conteúdo criado online é popular e gera retorno.

\section{CONSIDERAÇÕES FINAIS}

A leitura tem um papel fundamental na vida do indivíduo. Molda seu senso crítico, estimula sua empatia, apresenta diferentes culturas, amplia o vocabulário e o poder de argumentação. Seu estímulo é imprescindível, pois ter um exemplo é o primeiro passo para despertar a curiosidade para os livros.

Muitos leitores iniciam sua vida literária sendo incentivados por outras pessoas, seja família, amigos ou bibliotecários. Alguns são leitores desde sempre, outros vão descobrindo aos poucos o poder que a leitura tem. A verdade é que não existem regras, e o 
leitor deve ter total liberdade de escolher o que gosta, o que quer ler ou não. $E$, muitas vezes,

para atingir essa independência, o indivíduo conta com o incentivo e o apoio de quem o formou como leitor, o mediador de leitura.

Essa pesquisa mostrou que a mediação de leitura não se faz presente somente em casa, na escola ou na biblioteca, mas também na internet. Com o advento das TIC foram surgindo novas formas de leitura e a maneira como esta é tratada também foi se modificando.

Além dos e-books e leitores digitais, as TIC possibilitaram também a interação entre leitores. Foram surgindo redes de compartilhamento das quais os leitores começaram a se apropriar, encontrando pessoas com interesses em comum. As mídias sociais revolucionaram a experiência de leitura de muitos. São diversos os motivos para essas trocas literárias: ao ler determinado livro e não ter com quem conversar sobre ele, gostar tanto de uma obra e sentir a necessidade de escrever a respeito e compartilhar com outras pessoas a experiência de leitura.

Os objetivos dessa pesquisa foram atingidos ao constatar se que os Instagrans literários contribuem ativamente na mediação da leitura digital. É uma mídia social que tem ferramentas de fácil uso, dinâmica, totalmente interativa e proporciona um ambiente favorável para discutir literatura e, portanto, concluiu-se que o Instagram literário tem relação direta na mediação da leitura e os moderadores são, além de leitores, os mediadores da leitura.

A pesquisa verificou que é através das ferramentas que os bookstagrammers se apropriam que os leitores medeiam a leitura entre si e com seus seguidores. Seja através de uma resenha, que permite ao leitor conhecer do que se trata o livro, seja através das maratonas

e desafios literários, que estimulam o hábito constante da leitura.

O Instagram literário oferece formas simples de compartilhar e incentivar a leitura, de maneira casual, com linguagem clara e direta, estimulando a criatividade do bookstagrammer que, por exemplo, procura sempre mostrar elementos relacionados às histórias dos livros em suas fotos, aguçando assim a curiosidade do leitor. Da mesma forma, é simples também para o leitor, que consome de maneira acessível, enquanto está navegando pelo feed do Instagram, esses conteúdos através das fotos que chamam sua atenção, dos textos que não são extensos e que estão ao seu alcance na íntegra, sem precisar sair do Instagram e abrir outros links.

A principal característica do Instagram literário mostrou ser a interação. Nessa mídia social é possível interagir com leitores de qualquer lugar, autores brasileiros, editoras, enfim, é um espaço que possibilita diálogos abertos e trocas literárias de várias formas. Assim como as demais mídias sociais voltadas para leitores, o bookstagram é baseado em comunicação, e esse é um dos principais motivos que levam as pessoas a essa plataforma.

O Instagram literário mostrou ser um excelente espaço de disseminação da leitura, reunindo leitores, autores e pessoas que se interessam pelo universo literário em um espaço só. Acredita-se tratar de um ambiente favorável para que os profissionais da biblioteconomia e os que trabalham com o fomento à leitura se apropriem, trazendo a mediação da leitura para o ambiente digital.

O bibliotecário deve estar atento às mudanças tecnológicas e buscar leitores e potenciais leitores nos mais variados espaços, atentando-se às diferentes realidades de cada um, apresentando as diferentes formas de leitura, como os leitores digitais e aplicativos para leitores, que também são fontes de mediação da leitura. 
A pesquisa proporcionou uma visão mais aprofundada sobre o ambiente da mediação da leitura digital, que é um tema atual e um campo de estudo que pode ser explorado no âmbito da Biblioteconomia e da Ciência da Informação, assim como pelos profissionais que trabalham diretamente com o incentivo à leitura. Nos dias atuais é possível fazer quase tudo de forma online, e a mediação da leitura possui um amplo espaço para ser difundida e explorada digitalmente.

\section{REFERÊNCIAS}

ALMEIDA JÚNIOR, O. F. de; BORTOLIN, S. Mediação da Informação e da Leitura, 2007. In: SEMINÁRIO EM CIÊNCIA DA INFORMAÇÃO - UEL, 2., 2007, Londrina. Anais[...] Londrina: UEL, 2007. Disponível em: http://eprints.rclis.org/13269/. Acesso em: 27 jul. 2019.

BITTENCOURT, P. P. Bookstagrammers e sua influência no consumo de livros e objetos literários. 2017. Trabalho de Conclusão de Curso (Graduação em Comunicação Social - Produção Editorial) - Universidade Federal de Santa Maria, Santa Maria, 2017.

BORTOLIN, S. A ética na mediação da leitura na biblioteca escolar. Ensino Em ReVista, Uberlândia, v. 20, n. 2, p. 423-434, jul./dez. 2013.

CÂMARA, A. L. da M. S. A influência do Instagram no consumidor de viagens: uma análise da Voyage Turismo. 2019. Trabalho de Conclusão de Curso (Graduação em Administração) Universidade Federal de Campina Grande, Campina Grande, 2019.

CASTELLS, M. A sociedade em rede. 11. ed. São Paulo: Paz e Terra, 2012.

CORRÊA, L. Eu tenho "Insta": Infâncias, consumo e redes sociais, os usos e apropriações do aplicativo Instagram por crianças na cidade de São Paulo. 2015. Dissertação (Mestrado em Comunicação e Práticas de Consumo) - Escola Superior de Propaganda e Marketing, São Paulo, 2015.

DINIZ, J. P. A. Práticas de leitura nas mídias sociais: influências da mídia social Facebook na formação de leitores dos cursos de graduação do Instituto Federal Goiano - Campus Urutaí. In: INTERPROGRAMAS SECOMUNICA, 2., 2016, Brasília. Anais[...] Brasília: Universidade Católica de Brasília, 2016.

DUARTE, S. V.; FURTADO, M. S. V. Trabalho de conclusão de curso em ciências sociais aplicadas. São Paulo: Saraiva, 2014.

FAILLA, Z (org.). Pesquisa Retratos da leitura no Brasil. Rio de Janeiro: Sextante, São Paulo: Instituto Pró-Livro, 2016. Disponível em: http://prolivro.org.br/home/images/2016/RetratosDaLeitura2016_LIVRO_EM_PDF_FINAL_C OM_CAPA.pdf. Acesso em: 10 jun. 2019.

FISCHER, S. R. História da leitura. São Paulo: UNESP, 2006. 
GIL, A. C. Como elaborar projetos de pesquisa. São Paulo: Atlas, 2010.

HINERASKY, D. A. O Instagram como plataforma de negócio de moda: dos "itbloggers" às "it-marcas". In: CONGRESSO INTERNACIONAL EM COMUNICAÇÃO E CONSUMO, 4., 2014, São Paulo. Anais[...] São Paulo: ESPM, 2014.

KOCH, I. V.; ELIAS, V. M. Ler e compreender: os sentidos do texto. 3. ed. São Paulo: Contexto, 2010.

LÉVY, P. Cibercultura. 3. ed. São Paulo: Editora 34, 2011.

MARTINS, M. H. O que é leitura. São Paulo: Brasiliense, 2007.

MORAIS, C. R. de. Em torno dos bookstagrammers: leitura e compartilhamento de experiência em redes sociais. 2018. Trabalho de Conclusão de Curso

(Graduação em Letras Português) - Universidade Estadual da Paraíba, Campina Grande, 2018.

NUNES, M. S. C. Mediação da informação em bibliotecas universitárias

brasileiras e francesas. 2015. Tese (Doutorado em Ciência da Informação) - Universidade Federal da Bahia, Programa de Pós-Graduação em Ciência da Informação, Salvador, 2015.

PIRES, G. T. S. Fotografia através de dispositivos móveis: estudo de caso sobre o Instagram. 2012. Trabalho de Conclusão de Curso (Graduação em Publicidade e Propaganda) - Pontifícia Universidade Católica do Rio Grande do Sul, Porto Alegre, 2012.

ROCHA, A. Formação de mediadores de leitura: o sentido entre o texto e seu leitor. Hum. Publicações: Curitiba, 2017. E-book.

SANTOS, B. B. dos. Comunicação oral e mediação de leitura: formando leitores autores. In: ENCONTRO REGIONAL DOS ESTUDANTES DE BIBLIOTECONOMIA, 5., 2018, Belo Horizonte. Anais[...] Belo Horizonte: UFMG, 2018.

SANTOS NETO, J. A. Mediação da informação e da Leitura no Instagram: novas possibilidades para os bibliotecários. In: SÁ, Jéssica Patrícia Silva de; BARBOSA, Andreza Gonçalves; COSTA, Maria Elizabeth de Oliveira; SANTA ANNA, Jorge. (Org.). Bibliotecári@s e as redes sociais. 1. ed. Belo Horizonte: ABMG Editora, 2020. v. 1. p. 212-232.

SILVA, C. C. O. da. Blogs literários no incentivo à leitura. 2016. Trabalho de Conclusão de Curso (Graduação) - Curso de Biblioteconomia, Universidade Federal do Pará, Belém, 2016. 